\title{
Clinical Therapeutic Usage of Bichat Ball in Dentistry-A Review
}

\section{Lima Eduardo B, SÁ Carlos DL, Feitosa Victor P, De-Paula DM, Papaléo RF, Melo Radamés B}

Paulo Picanço School of Dentistry/Rua Joaquim Sá 900, Fortaleza, Brazil

\begin{abstract}
The Bichat ball is fat located in the cheeks region, which can be used for various therapeutic purposes. The aim of the present study is to carry out a literature review on the use of Bichat ball and its application for aesthetic and functional issues. A search was performed on PubMed; SciELO, Scopus and Lilacs databases using the keywords we found 76 articles and 8 were selected, based on exclusion criteria (laboratory studies, articles in a language other than English, and literature reviews). The title and abstract of articles that met the inclusion criteria were evaluated. Some articles mentioned the use of the Bichat ball for the repair of small oral defects, such as oroantral communication closure, peri-orbital defects, congenital cleft palate, facial plastic surgery; some treatments were associated with pathologies. Further articles quoted its use for aesthetic purposes such as facial feminization and diminishing of the child's cheek appearance. Thus, the Bichat ball is effective for various purposes and can be used for both aesthetic and functional therapeutic treatment.
\end{abstract}

Key Words: Buccal fat pad, Bichat ball, Bichectomy

\section{Introduction}

Bichat ball (BFP) is a fat ball that is located in the region of the cheeks, anterior to the masseter muscle and lateral to the buccinator muscle. Bichat's ball is named after Marie François Xavier Bichat, a French physiologist, and anatomist who described the ball of fat located in the region of the cheeks [1].

When we talk about bichectomy that consists of the removal of the BFP we have an aesthetic and functional purpose, as well as reducing the cheek mucosa nicking it also improves the facial contour leaving the patient with a more elongated and tapered face, decreasing the rounded and childish aspect. For these characteristics, the procedure has been much sought after in dental offices [2].

The Bichat ball is also used for the repair of small oral defects, such as the closure of oroantral communication, periorbital defects, congenital cleft palate, plastic surgery of facial re-alignment, facial feminization [3].

Oroantral communication is a relatively common complication in dentistry, as well as the search for patients for bichectomy surgery, is common. Thus, professionals need to have a good knowledge about the BFP and its various purposes of use, since even if the procedure for accessing it is simple, the professional requires a good anatomical knowledge and surgical techniques, since the fat ball is located in a region very close to the terminal branches of the facial nerve, facial artery, facial vein and parotid duct [4].

Thus, the present study aims to report on the uses of Bichat's greasy ball and its various aesthetic and/or functional purposes by means of a literature review.

\section{Materials and Methods}

\section{Data source}

This work was carried out through researches in Pubmed, SciELO, Scopus and Lilacs databases. The selected articles are from the year 1995 to 2018, searched on December 19, 2018. A total of 76 articles were found, where 53 were excluded because they did not meet the inclusion and exclusion criteria. Of the 23 remaining articles, 15 were excluded after reading because they did not have a good postoperative follow-up (Table 1).

Table 1. Spreading of literature search.

\begin{tabular}{|l|l|}
\hline Detail & Number of articles \\
\hline Found in PubMed & 15 \\
\hline Found in SciELO & 8 \\
\hline Found in Scopus & 25 \\
\hline Found in Lilacs & 28 \\
\hline Total articles found & 76 \\
\hline $\begin{array}{l}\text { Excluded after inclusion and exclusion } \\
\text { criteria }\end{array}$ & 53 \\
\hline Excluded after reading abstracts & 15 \\
\hline Selected articles & 8 \\
\hline
\end{tabular}

The inclusion criteria were articles published in English, case reports and clinical trials. Exclusion criteria were laboratory studies, articles in a language other than English, and literature reviews. The title and summary of articles that met the inclusion and exclusion criteria were evaluated. The articles were found using the descriptors "buccal fat pad", "Bichat ball" and "bichectomy".

\section{Results}

A portion of the studies reported using the Bicaht ball for aesthetic purposes, such as facial feminization surgery, facial plastic surgery, and surgery to reduce the appearance of the face. However, other studies report the application for functional purposes, such as reduction of nibbling, closure of oroantral communication, peri-orbital defects, congenital cleft palate, intraoral reconstruction after removal of odontogenic cyst and reconstruction of intraoral defects. In addition, some articles report the study of a series of patients and the success of the use of BFP in them. The evaluation of the patients 
included in the studies was from 1 month to 15 years. The details of the selected articles are presented in Table 2.

Table 2. Details of selected articles.

\begin{tabular}{|c|c|c|c|c|}
\hline Article & $\begin{array}{ll}\text { Number } & \text { of } \\
\text { participants }\end{array}$ & Evaluation time & Goal & Main findings \\
\hline Adam et al., [5] & 300 & 15 years & Functional & $\begin{array}{l}\text { The study reports the effectiveness of the Bichat ball at the closure of } \\
\text { oro-sinusal communication. }\end{array}$ \\
\hline Altman et al., [6] & 5 & 3 months & Aesthetics & $\begin{array}{l}\text { The study analyzes the use of bichectomy in Facial Feminization } \\
\text { Surgery (FFS). }\end{array}$ \\
\hline Rai et al., [7] & 20 & 20 months & Functional & $\begin{array}{l}\text { The study concluded that the buccal fat pad is the best choice for } \\
\text { reconstruction of intraoral defects compared to the nasolabial flap. }\end{array}$ \\
\hline Alonso et al., [8] & 9 & 6 months & Functional & $\begin{array}{l}\text { The study reports the success of oroantral closure using the buccal fat } \\
\text { pad. }\end{array}$ \\
\hline Choi et al., [9] & 1 & 6 months & Functional & $\begin{array}{l}\text { The authors report the use of the pedicled Bichat ball for intraoral } \\
\text { reconstruction after removal of the odontogenic cyst. }\end{array}$ \\
\hline Roman et al., [3] & 1 & 1 month & $\begin{array}{l}\text { Functional and } \\
\text { Aesthetic }\end{array}$ & $\begin{array}{l}\text { The oral fat pad can be used in cases of oroantral communication, peri- } \\
\text { orbital defects, congenital cleft palate, and facial plastic surgery. }\end{array}$ \\
\hline Faria et al., [10] & 59 & 12 a 26 months & Aesthetics & $\begin{array}{l}\text { Removal of portions of Bichat fats is safe as long as the anatomical } \\
\text { details are observed. It can offer greater harmony between three-thirds } \\
\text { of the face. }\end{array}$ \\
\hline Alvarez et al., [4] & 27 & 11 months & Aesthetics & $\begin{array}{l}\text { The removal of oral fat can be performed safely, providing a volumetric } \\
\text { decrease of the lower facial third, with greater enhancement of facial } \\
\text { contours. }\end{array}$ \\
\hline
\end{tabular}

\section{Discussion}

Among the articles researched, most reports about the use of the Bichat ball in the oroantral communication closure, three of the selected eight reports or at least mentioned the technique. To get an idea of the success of this type of surgical technique application, one of the articles selected [5] reports a study of 300 patients over 15 years without any recurrence of the communication, demonstrating the optimal transformation of adipose tissue over time. Several other articles have reported a series of cases involving patients who underwent oroantral communication closure using the greasy ball and in the postoperative period, no sign of recurrence was seen.

In addition to being used for oroantral communication closure, Bichat's greasy ball is used for the repair of several intraoral defects [3]. These defects are of genetic origin, due to pathologies and other factors, so the selected studies report the use of fat for peri-orbital defects, congenital cleft palate, and facial plastic surgery. In addition, one study also concluded that for cases of reconstruction of intraoral defects buccal fat is a better choice compared to the nasolabial flap.

The Bichat ball has a large number of mesenchymal stem cells with great differentiation potential, in this way it is seen as a promising source of progenitor cells. A recent study [11] conducted experiments in animals with the aim of inducing the formation of mineralized tissue for the treatment of osteoporosis from cells derived from adipose tissue and the result was promising. In the case of an evolution of the studies in this sense, the use of the ball of Bichat, mainly for functional purposes, would gain even more relevance.

The use of BFP for aesthetic purposes is not just a matter of softening the child's or rounded aspect of the face, one of the selected articles talks about the use of the procedure for facial feminization that consists of a series of surgical techniques to leave the face with a more and one of the surgeries used is bichectomy. The technique of facial feminization is widely used by transsexuals and women who have a very masculine face [6].

There is a study [1] that used ultrasonography to evaluate the patient in the preoperative period, assessing the location of the adipose body, its volume and extension, in order to improve the diagnosis and evaluate if bichectomy is really necessary, helping to reduce the number of unnecessary surgeries and decrease the patient's expectation for a result that is often not obtained, especially when it comes to the aesthetic purpose of the surgery.

\section{Conclusion}

In this way, the use of Bichat ball is extremely simple, having many purposes and can be used in various procedures, be they of aesthetic and/or functional nature.

\section{References}

1. Jaeger F. A novel preoperative ultrasonography protocol for prediction of bichectomy procedure. Arquivo Brasileiro de Odontologia. 2016; 12.

2. Tostevin PMJ. The buccal pad of fat: A review. Clinical Anatomy. 1995; 8: 403-406.

3. Roman Torres CVG, Sani AJ, Cordeiro J, Filho SM, Sampaio RMF, et al. Bichat's buccal fat pad removal: Cheek reduction surgery. Journal of Dental Health, Oral Disorders and Therapy. 2017; 7: 00250.

4. Alvarez GS, Siqueira EJ. Bichectomy: technical systematization applied in 27 consecutive cases. Brazilian Journal of Plastic Surgery. 2018; 33: 74-81.

5. Adam P, Mercier J, Billet J, Huet P. The Bichat ball. The surgical value of oro-sinus communications. The Revue de Stomatologie Chirurgie Maxillo-faciale et de Chirurgie Orale. 1995; 96: $379-384$. 
6. Altman K. Facial feminization surgery: current state of the art. International Journal of Oral and Maxillofacial Surgery. 2012; 41: 885-894.

7. Rai A, Datarkar A, Rai M. Is buccal fat pad a better option than nasolabial flap for reconstruction of intraoral defects after surgical release of fibrous bands in patients with oral submucous fibrosis? A pilot study: a protocol for the management of oral submucous fibrosis. Journal of Cranio Maxillofacial Surgery. 2014; 42: e111-116.

8. Alonso González R. Closure of oroantral communications with Bichat's buccal fat pad. Level of patient satisfaction. Journal of Clinical and Experimental Dentistry. 2015; 7: 28-33.
9. Choi HJ, Lee JB. Obliteration of recurrent large dentigerous cyst using bilateral buccal fat pad sling flaps. Journal of Craniofacial Surgery. 2016; 27: e465-468.

10. Faria CADC, Dias RCS, Campos AC. Bichectomy and its contribution to facial harmony. Brazilian Journal of Plastic Surgery. 2018; 33: 446-452.

11. Uri O, Behrbalk E, Folman Y. Local implantation of autologous adipose-derived stem cells increases femoral strength and bone density in osteoporotic rats: A randomized controlled animal study. Journal of Orthopaedic Surgery (Hong Kong). 2018; 26: 2309499018799534. 